\title{
The Mycorrhiza Fungus Piriformospora indica Induces Fast Root-Surface pH Signaling and Primes Systemic Alkalinization of the Leaf Apoplast Upon Powdery Mildew Infection
}

\author{
Hubert H. Felle, ${ }^{1}$ Frank Waller, ${ }^{2}$ Alexandra Molitor, ${ }^{2}$ and Karl-Heinz Kogel ${ }^{2}$ \\ ${ }^{1}$ Botanisches Institut I, Justus-Liebig-Universität, Senckenbergstrasse 17, D-35390 Gießen, Germany; ${ }^{2}$ Interdisziplinäres \\ Forschungszentrum für Umweltsicherung, Institut für Phytopathologie und Angewandte Zoologie, Justus-Liebig-Universität, \\ Heinrich-Buff-Ring 26-32, D-35392 Gießen, Germany
}

Submitted 11 December 2008. Accepted 14 May 2009.

\begin{abstract}
We analyze here, by noninvasive electrophysiology, local and systemic plant responses in the interaction of barley (Hordeum vulgare $\mathrm{L}$.) with the root-colonizing basidiomycete Piriformospora indica. In the short term (seconds, minutes), a constant flow of $P$. indica chlamydospores along primary roots altered surface $\mathbf{p H}$ characteristics; whereas the root-hair zone transiently alkalized-a typical elicitor response- the elongation zone acidified, indicative of enhanced $\mathrm{H}^{+}$extrusion and plasma membrane $\mathrm{H}^{+}$ATPase stimulation. Eight to $10 \mathrm{~min}$ after treating roots with chlamydospores, the apoplastic $\mathrm{pH}$ of leaves began to acidify, which contrasts with observations of an alkalinization response to various stressors and microbe-associated molecular patterns (MAMPs). In the long term (days), plants with $P$. indica-colonized roots responded to inoculation with the leaf-pathogenic powdery mildew fungus Blumeria graminis f. sp. hordei with a leaf apoplastic $\mathrm{pH}$ increase of about 2, while the leaf apoplast of noncolonized barley responded to $B$. graminis f. sp. hordei merely with a pH increase of 0.8 . The strong apoplastic pH response is reminiscent of $B$. graminis f. sp. hordei-triggered $\mathrm{pH}$ shifts in resistance gene-mediated resistant barley leaves or upon treatment with a chemical resistance inducer. In contrast, the MAMP $\mathrm{N}$-acetylchito-octaose did not induce resistance to $\mathrm{B}$. graminis f. sp. hordei and did not trigger the primed apoplastic pH shift. We speculate that the primed $\mathrm{pH}$ increase is indicative of and supports the potentiated systemic response to $B$. graminis f. sp. hordei-induced by $P$. indica in barley.
\end{abstract}

Piriformospora indica is the model species for the recently delineated fungal order Sebacinales (phylum Basidiomycota) that comprises a great variety of root-colonizing mycorrhiza fungi with a broad host range among mono- and dicotyledonous plants (Schäfer and Kogel 2009; Schäfer et al. 2007; Verma et al. 1998). The symbiotic fungus bears an attractive agronomic prospect, since root colonization of host plants confers resistance to root as well as shoot diseases and tolerance to abiotic stress (Baltruschat et al. 2008; Deshmukh et al. 2006; Stein et al. 2008). In barley, a significant increase in grain yield was observed under outdoor conditions when seedlings were inoculated with the fungus (Waller et al. 2005).

Corresponding author: H. H. Felle; Telephone +49 (0) 641 9935126; Fax: +49 (0) 641 9935119; E-mail: Hubert.Felle@bio.uni-giessen.de
Colonization of barley roots with $P$. indica involves chlamydospore germination and extracellular colonization of the root within 1 to 2 days after inoculation (dai), penetration of single rhizodermal cells, and formation of the first intercellular hyphae 3 dai. At 7 dai, large areas of the root are colonized by inter- and intracellular hyphae, and from about 10 dai onward, fungal sporulation is frequently observed. The fungus does not enter vascular tissue nor is it detectable in stems or leaves. Instead, it shows a preference for developmentally 'older' tissue, since it largely colonizes the root-hair zone rather than the elongation and meristematic zone proximal to the root tip (Deshmukh et al. 2006). Despite an extensive colonization by $P$. indica, roots do not show any macroscopic evidence for tissue impairment or necrotization. Instead, root and shoot biomass is considerably enhanced by fungal colonization (Waller et al. 2005).

Among the benefits transferred to cereal hosts are resistance against necrotrophic root and stem base pathogens, such as Fusarium spp. and Pseudocercosporella herpotrichoides, as well as systemic resistance against the leaf powdery mildew pathogen Blumeria graminis (Deshmukh and Kogel 2007; Serfling et al. 2007; Waller et al. 2005). The molecular mechanism of systemic resistance conferred by $P$. indica to powdery mildew was studied in Arabidopsis thaliana. Genetic dissection of the resistance reaction revealed requirement of an operative jasmonate pathway for systemic responses to powdery mildew fungus Golovinomyces orontii (Stein et al. 2008), reminiscent of the induced systemic resistance (ISR) pathway activated by rhizobacteria (Van Wees et al. 2008). In barley, gene expression profiling of leaves from $P$. indica-colonized plants showed few systemic changes in gene expression (Waller et al. 2008), which is consistent with an ISR-like resistance mechanism (Van Loon et al. 1998). On the other hand, gene expression profiling of colonized barley roots at 1,3 , and 7 dai with $P$. indica revealed differential regulation of about 1,300 genes out of approximately 40,000 probe sets present on a microarray (Schäfer et al. in press).

Successful colonization of roots by $P$. indica requires plant defense suppression, although the fungus, by the same time, induces local and systemic resistance to fungal pathogens once the symbiosis is established. Hence, we were interested in analyzing, preferably early, local and systemic responses of the plant root and leaf to an encounter with the symbiotic fungus. Using established electrophysiological techniques, we investigated the immediate effects of the first encounter of barley 
roots with $P$. indica chlamydospores and the consecutive transfer of signals from roots to leaves. Since protons are multifunctional in that they i) provide the basic condition in which biochemical reactions take place, ii) are consumed or are produced in such reactions, iii) are part of the transmembrane driving force, and iv) represent a signaling compound, the knowledge of their activity is indispensable for a more comprehensive understanding of host-microbe interactions. Leaf apoplastic proton activity has been visualized by noninvasive microprobe techniques in the interaction of barley with powdery mildew fungus Blumeria graminis f. sp. hordei (Felle et al. 2004). These investigations revealed a close correlation between pathogen-induced local $\mathrm{pH}$ changes and defense responses conferred by resistance $(R)$ genes. Here, we demon-
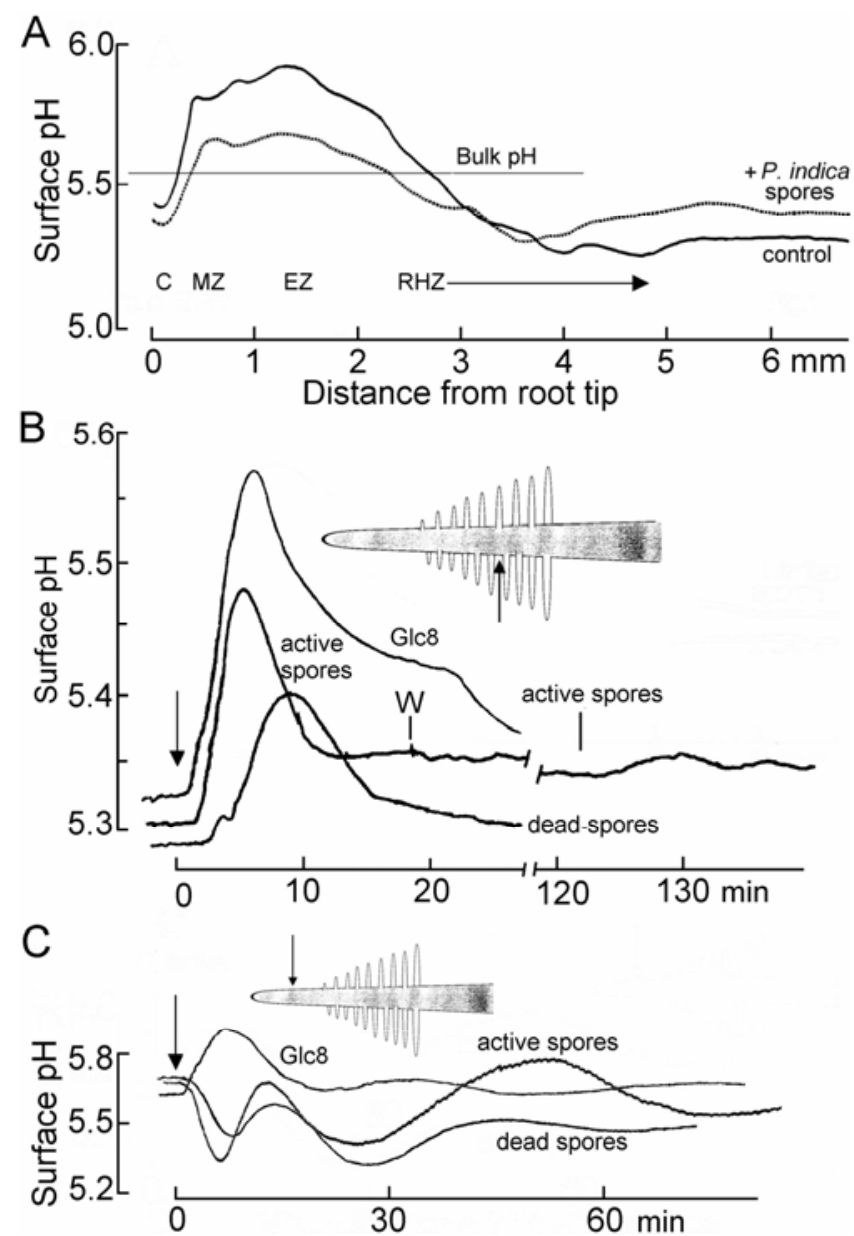

Fig. 1. Surface $\mathrm{pH}$ responses of barley roots to the addition of Piriformospora indica chlamydospores, measured with a $\mathrm{pH}$-sensitive microelectrode at a distance of $5 \mu \mathrm{m}$ from the surface. A, Surface profiles were taken before (control) and 30 min after the addition of $P$. indica chlamydospores. Bulk pH denotes the $\mathrm{pH}$ in the medium at least $5 \mathrm{~mm}$ away from the root surface. $\mathrm{C}=$ calyptra, $\mathrm{MZ}=$ meristematic zone, $\mathrm{EZ}=$ elongation zone, and RHZ = root hair zone. Representative example of 5 equivalent tests. B, Immediate surface $\mathrm{pH}$ response of a barley root to the addition of active or dead $P$. indica chlamydospores or $0.1 \mu \mathrm{M} \mathrm{N}$-acetylchito-octaose (Glc8), as indicated. The $\mathrm{pH}$ electrode was positioned within the root-hair zone (arrow of inset). Once a stable $\mathrm{pH}$ baseline was attained during flowthrough ( 3 to $4 \mathrm{ml}$ of medium per min), the medium (with the spores or Glc8) was added and the $\mathrm{pH}$ response was measured. After removing the active spores from the solution (W), spores were added again after about $100 \mathrm{~min}$. Response time was extrapolated after the experiment by adding a solution of $\mathrm{pH} 7$ (not shown). Kinetics are representative of eight equivalent tests (active spores) and three tests with dead spores or Glc8. C, As in $\mathrm{B}$, except the electrode position is within the elongation zone (arrow of inset). Spores were added after a stable $\mathrm{pH}$ baseline was attained. Kinetics are representative of four equivalent tests each. strate that the barley root responds within seconds to the first contact with chlamydospores of $P$. indica with specific shifts in the surface $\mathrm{pH}$ and that signals evoked there are rapidly transferred to the leaves. In the long term (days), the contact of the root with chlamydospores primes leaves for a strong apoplastic alkalinization and disease resistance in response to challenge inoculation with the powdery mildew fungus. This alkalinization reaction is reminiscent of the apoplastic $\mathrm{pH}$ changes induced in barley both by treatment with the chemical resistance inducer benzo(1,2,3)thiadiazole-7-carbothioic acid $S$-methyl ester (BTH) or in resistance $(R)$ gene-mediated powdery mildew resistance.

\section{RESULTS}

\section{Short-term effects of $\boldsymbol{P}$. indica chlamydospores on surface $\mathrm{pH}$ of barley roots.}

The surface $\mathrm{pH}$ of plant primary roots is a sensitive parameter for detecting metabolic changes activated or elicited by microbe-associated molecular patterns (MAMPs) and other elicitors. Roots of Medicago sativa have been demonstrated to respond specifically to Nod factors and to chitin fragments with a variety of ion fluxes (Felle et al. 1998). The surface $\mathrm{pH}$ is not uniform along the root but displays a typical pattern along the different zones, which seems to be generated by different transport activities (Felle 1998; Monshausen et al. 1996; Weisenseel et al. 1979). In order to test for a response of the barley root to chlamydospores, we recorded the $\mathrm{pH}$ profile over the different root zones along the first $7 \mathrm{~mm}$ from the tip of the primary root before (control) and $30 \mathrm{~min}$ after the addition of chlamydospores (Fig. 1A). At the elongation zone (EZ) of 3-day-old seedlings, the surface $\mathrm{pH}$ was less acidic than the medium bulk $\mathrm{pH}$, while it was more acidic in the root hair zone (RHZ). After addition of chlamydospores $\left(2 \times 10^{4}\right.$ to $5 \times$ $10^{4}$ spores $\mathrm{ml}^{-1}$ ), the difference of the outer $\mathrm{pH}$ around the different zones was less pronounced, i.e., the $\mathrm{pH}$ in EZ was more acidic (mean $\Delta \mathrm{pH} 0.22 \pm 0.09$ standard error $[\mathrm{SE}] ; n=5$ ), while the $\mathrm{pH}$ in $\mathrm{RHZ}$ was less acidic (mean $\Delta \mathrm{pH} 0.12 \pm 0.05$ $\mathrm{SE}$ ) compared with untreated roots. As shown by a kinetic analysis in the range of $140 \mathrm{~min}$ after inoculation, the response of RHZ to chlamydospores was a delayed transient alkalinization peaking about 5 min after the first encounter (Fig. 1B, mean of maximal $\mathrm{pH}$ change $0.17 \pm 0.04 \mathrm{SE} ; n=8$ ). Removing the chlamydospores had no significant effect. Consistently, a second succeeding inoculation of the roots with chlamydospores $2 \mathrm{~h}$ after the first encounter yielded only a minor $\mathrm{pH}$ change indicating that the barley root responded refractory (Fig. 1B). Such a behavior has been found to be typical for symbiotic interactions, e.g., for the responses of root hairs (depolarization, surface $\mathrm{pH}$ ) to Nod factors (Felle et al. 1998). Tests with $\mathrm{N}$-acetylchito-octaose (Glc8) and dead chlamydo-

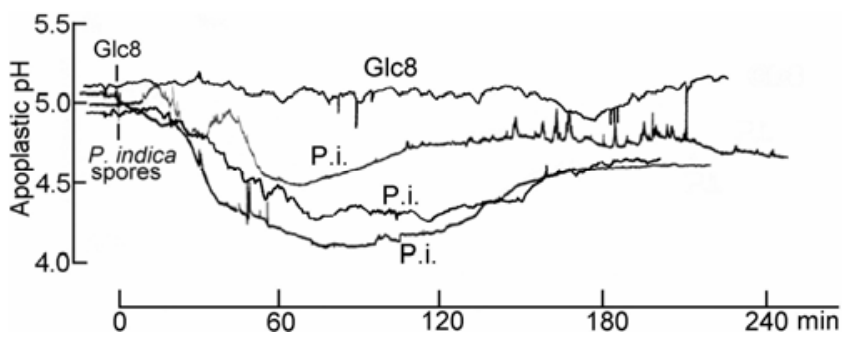

Fig. 2. Short-term response of the barley leaf apoplast to root encounter with Piriformospora indica chlamydospores (P.i., three independent experiments) or to $0.1 \mu \mathrm{M} \mathrm{N}$-acetylchito-octaose (Glc8). Apoplastic pH was measured with microelectrodes positioned in the cavities of open stomata. The distance from the root to the leaf was about $24 \mathrm{~cm}$. 
spores yielded similar kinetics, whereby the roots responded more strongly to the chitin fragments and more weakly to the dead spores as compared with the active spores (Fig. 1B). The immediate $\mathrm{pH}$ response of EZ to chlamydospores was different. As shown in Figure 1C, after a delay of 10 to $15 \mathrm{~s}$, surface $\mathrm{pH}$ first decreased and then turned into a damped oscillation. Whereas the roots responded with a similar oscillation to dead spores, addition of the chitin fragments caused a transient $\mathrm{pH}$ increase, like the one observed in the RHZ (Fig. 1C). This indicates that the $\mathrm{pH}$ response to chlamydospores of $P$. indica is not simply based on elicitor-active chitin from chlamydospore walls.

\section{Short-term direct effects of root inoculation with $P$. indica on barley leaf apoplastic $\mathbf{p H}$.}

Chlamydospores added to the roots of intact 3-week-old barley plants caused an acidification of the leaf apoplast (Fig. 2). At 5 to $8 \mathrm{~min}$ after flushing the chlamydospores along the root, leaf apoplastic $\mathrm{pH}$ started to decrease and, after peaking after about $60 \mathrm{~min}$, partly recovered. The maximal $\mathrm{pH}$ change was between 0.5 and 1.1 (mean $0.86 \pm 0.21 \mathrm{SE}, n=5$ ). This data demonstrates that the mycorrhiza fungus induces an immediate strong and systemic response in the leaf well before hyphal colonization of the root tissue. The chitin oligomer Glc8, which transiently increases the root surface pH (Fig. 1B and $\mathrm{C}$ ), did not affect leaf apoplastic $\mathrm{pH}$.

\section{Priming of leaf apoplast pH by $\boldsymbol{P}$. indica root colonization.}

Apoplastic $\mathrm{pH}$ increase is a typical response of barley leaves to an inoculation with conidia of the powdery mildew fungus B. graminis f. sp. hordei. Notably, the magnitude and the kinetic profile of alkalinization were shown to be associated with the defense phenotype conferred by specific $R$ genes (Felle et al. 2004, 2005). In a compatible interaction with $B$. graminis f. $\mathrm{sp}$. hordei, barley leaves display merely a minor $\mathrm{pH}$ response to fungal inoculation, while incompatible interactions governed by $R$ gene $M l g$ or Mla12, in contrast, result in a massive $\mathrm{pH}$ increase of over $2 \mathrm{pH}$ units (Felle et al. 2004). Consistently, an increase in leaf apoplastic $\mathrm{pH}$ was also seen in barley challenged by $B$. graminis when plants were pretreated with the resistance inducer BTH (Felle et al. 2008). Since it has also been shown that root colonization by $P$. indica results in induced systemic resistance to powdery mildew (Waller et al. 2005), we addressed the question of whether $P$. indica mimics a chemical resistance inducer or $R$ genes on the level of leaf

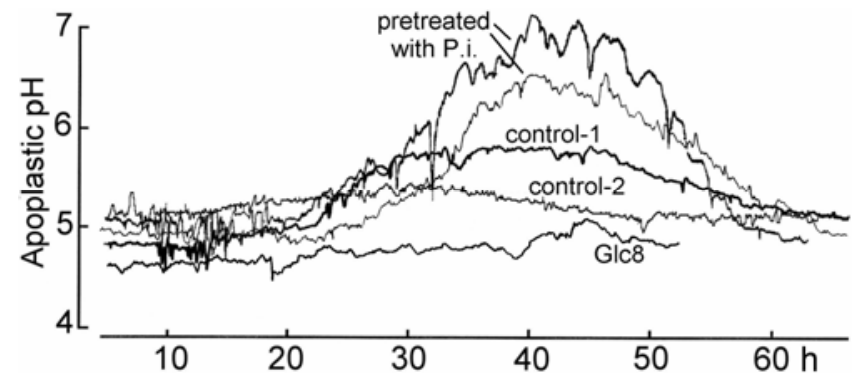

Fig. 3. Apoplastic long-term $\mathrm{pH}$ response of barley, which is susceptible to powdery mildew, to various treatments. Pretreated $=$ two examples of the apoplastic $\mathrm{pH}$ response of a plant (susceptible to Blumeria graminis $\mathrm{f}$. $\mathrm{sp}$. hordei A6) after root inoculation with Piriformospora indica and inoculation with B. graminis f. sp. hordei A6 conidia (mean maximal pH increase of $1.82 \pm 0.24$ standard error [SE]; $n=5$ ). Control- $1=$ apoplastic $\mathrm{pH}$ of a plant inoculated with $B$. graminis f. sp. hordei A6 (mean maximal pH increase of $0.81 \pm 0.16 \mathrm{SE} ; n=5)$. Control- $2=$ apoplastic $\mathrm{pH}$ response of a plant after root inoculation with $P$. indica (mean maximal $\mathrm{pH}$ increase of $0.27 \pm 0.05 \mathrm{SE} ; n=5$ ). Glc8 = apoplastic $\mathrm{pH}$ response of a plant after root treatment with $0.1 \mu \mathrm{M} \mathrm{N}$-acetylchitooctaose. apoplastic $\mathrm{pH}$ changes. To this end, we compared apoplastic leaf $\mathrm{pH}$ changes in barley cv. Ingrid, either root-inoculated or not inoculated with $P$. indica, upon challenge with the virulent powdery mildew race $B$. graminis f. sp. hordei A6. In $P$. indica-inoculated plants, a strong increase in leaf $\mathrm{pH}$ of $>2$ was recorded in the time range of about 25 to $55 \mathrm{~h}$, with a peak at about $40 \mathrm{~h}$ after inoculation (hai). Root-inoculation with $P$. indica without subsequent challenge with $B$. graminis f. sp. hordei A6 conidia or B. graminis f. sp. hordei challenge of leaves from $P$. indica-free plants did not cause this leaf apoplastic $\mathrm{pH}$ increase, neither did $0.1 \mu \mathrm{M}$ Glc8 added to the roots (Fig. 3).

\section{Effect of chlamydospores and Glc8} on systemic powdery mildew resistance.

In order to substantiate in the above experimental setup that root inoculation with $P$. indica chlamydospores leads to enhanced resistance against powdery mildew, we assessed colonization of barley leaves with $B$. graminis f. sp. hordei A6 in a leaf segment test. At 3 days after treatment of roots of hydroponically grown plants with chlamydospores or $0.1 \mu \mathrm{M}$ Glc8, leaves were detached and inoculated with powdery mildew conidia. After 6 days, the number of powdery mildew pustules was determined (Fig. 4). Compared with mock-treated control plants, root inoculation with chlamydospores led to a $22 \%$ reduction of powdery mildew pustules. In contrast, treatment of Ingrid roots with Glc8 did not result in a reduction of $B$. graminis f. sp. hordei colonies, while BTH (40 mg/liter) used as a positive control exhibited a strong inhibitory effect $(44 \%$ reduction) on B. graminis f. sp. hordei development.

\section{DISCUSSION}

Here, we demonstrate local and systemic effects of $P$. indica chlamydospores on root surface $\mathrm{pH}$ and on apoplastic $\mathrm{pH}$ in leaves of barley before and after challenge-inoculation with the powdery mildew fungus. The surface $\mathrm{pH}$ of a root represents the extension of its apoplast (Felle 1998). Since the un-

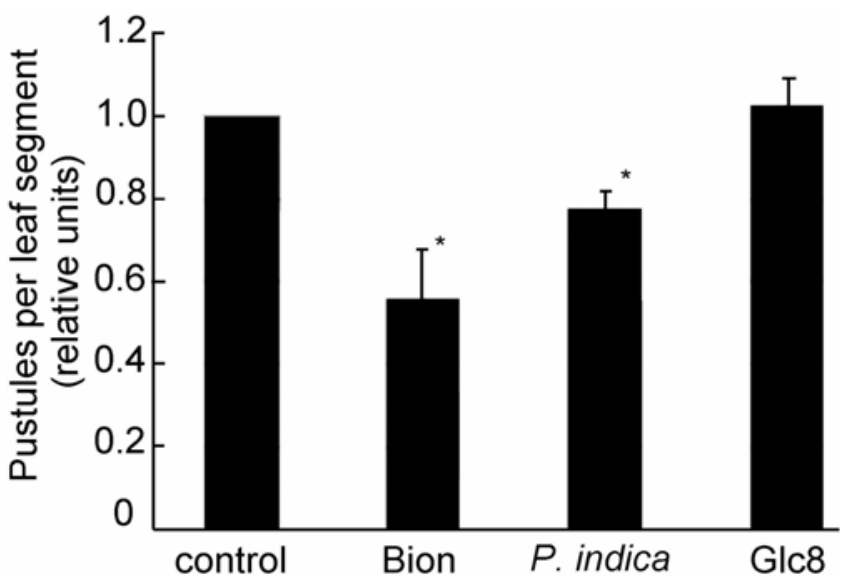

Fig. 4. Development of powdery mildew pustules on leaves of barley plants after root inoculation with different factors. Roots of hydroponically grown barley plants were inoculated with benzo(1,2,3)thiadiazole-7-carbothioic acid $S$-methyl ester (40 mg per milliliter), Piriformospora indica chlamydospores $(150,000$ spores per milliliter), or $N$-acetylchito-octaose (Glc8). Three days after treatment, the youngest fully expanded leaves were detached and inoculated with powdery mildew spores, and development of powdery mildew pustules was determined 5 days after inoculation. The number of pustules for mock-treated control plants was set to 1 and relative values for the different treatments are shown. Values are means of three or four independent experiments, with each set consisting of 24 plants. Error bars represent standard error of the mean values, asterisks indicate a significance level of $P<0.05$ (Student's $t$-test of respective treatment compared to control). 
disturbed surface-water layer extending into the bulk is rather thin, changes in ion concentration or transport activity induced by elicitors is an indicator of an altered $\left(\mathrm{H}^{+}-\right)$signaling arising from an activation or deactivation of the plasma membrane $\mathrm{H}^{+}$ ATPase and, thereby, mediated $\mathrm{H}^{+}$cotransport. Thus, changes in surface $\mathrm{H}^{+}$activity are characteristic for symbiotic responses, as shown for the Nod factor-legume interactions in Medicago sativa (Ehrhardt et al. 1992; Felle et al. 1998) and Lotus japonicus (Radutoiu et al. 2003) for stress reactions in which apoplastic $\mathrm{pH}$ has been demonstrated to be a sensitive major variable (Felle and Hanstein 2002; Felle et al. 2005; Wilkinson 1999) as well as for the activation of defense responses (Felle et al. 2004).

\section{Differential responses at the root surface.}

The surface $\mathrm{pH}$ measured along primary roots clearly showed areas with a $\mathrm{pH}$ less acidic than the bulk in the EZ but more acidic in the RHZ and at the calyptra. About 30 min after flushing the primary root with $P$. indica chlamydospores, the differential $\mathrm{pH}$ profile changed and appeared less pronounced. However, spot kinetics taken in EZ (Fig. 1C) and RHZ (Fig. 1B) reveal that the immediate responses are transiently stronger than the steady-state values in Figure 1A.

Responses of plant cells to MAMPs, i.e., fungal chitin or fragments thereof, are well known and reported as a distinct, mostly transient $\mathrm{pH}$ increase (Baureithel et al. 1994; Felix et al. 1993). These earlier findings are corroborated and extended in that an electrode placed between root hairs displayed an alkalinization in intact RHZ tissue in response to $P$. indica, a basidiomycota that contains chitin in its hyphae (Deshmukh et al. 2006) (Fig. 1B). This notion is supported by the observation that $0.1 \mu \mathrm{M}$ Glc8 caused a similar $\mathrm{pH}$ response. Compared with the $\mathrm{pH}$ changes found by Felix and associates (1993) and Baureithel and associates (1994), the $\mathrm{pH}$ increase observed here is relatively small and reaches only about 0.2 to 0.3 . This may be due to the experimental design; the root's contact with the chlamydospores is not very tight and the actual amount of one or more MAMP elicitors that are released by the fungal hyphae thereby coming into contact with the putative MAMP receptors may be low. Moreover, since there is a constant flow of medium, part of the effect may have been diluted out, so that the actual $\mathrm{pH}$ increase experienced by the root during a natural colonization would have been more substantial. Also, dead chlamydospores caused a transient alkalinization, which supports the notion that we are observing a typical chitin response in the RHZ.

The relatively short $\mathrm{pH}$ transient is also reminiscent of the reaction of legume (Medicago sativa) roots to Nod factors secreted by nitrogen-fixing bacteria and is in this way associated with the establishment of a root symbiosis (Felle et al. 1998). However, as the plant's response to Nod factors and chitin fragments was found indistinguishable in terms of timing and amplitude, it is not possible to decide whether the root response to $P$. indica was a defense reaction or a response critical at the onset of the symbiosis. The fact that PR genes like pathogenesis-related 1 are expressed at slightly higher levels in $P$. indicainoculated barley roots during the first 3 dai (Deshmukh and Kogel 2007) would argue in favor of a transiently enhanced defense response. In a previous study by Felle and associates (1998) as well as in our analysis, two distinct characteristics were observed in response of roots to either treatment, the Nod factor and the chlamydospores: i) a lag-phase that excludes a direct membrane effect but, rather, points to launching of an intracellular signal cascade and ii) in support of this, a refractory behavior.

Whereas the alkalinization effect in the RHZ could have been expected (although acidification following elicitor appli- cation has been reported in tomato cell suspensions [VeraEstrella et al. 1994]), the response within the EZ was not. In this zone an initial $P$. indica-induced acidification turned into a damped oscillation. Whereas dead spores were responded to with similar kinetics, as found in the RHZ, chitin fragments caused the typical transient alkalinization. This indicates that there is more (specific) information in the spores than just chitin.

Whatever about the oscillation, which probably is a regulatory phenomenon, the observation that most of the kinetics is on the acidification side is very likely indicative of an activation of $\mathrm{H}^{+}$export, e.g., by the plasma membrane $\mathrm{H}^{+}$ATPase. Such an activation of the EZ could indicate faster cell growth, an effect actually measured as root biomass increase, induced by $P$. indica (Achatz 2006; Waller et al 2005). In addition, the observed induction of resistance by $P$. indica but not by inoculation with chitin (Figs. 3 and 4) indicates that mechanisms distinct from elicitor-mediated responses or different elicitors than chitin lead to systemic resistance against powdery mildew. This finding is consistent with a recent report showing that a cell-wall extract from $P$. indica promotes growth of Arabidopsis seedlings and induces a transient cytosolic $\mathrm{Ca}^{++}$ elevation in roots but does not stimulate defense responses such as $\mathrm{H}_{2} \mathrm{O}_{2}$ production and defense gene activation (Vadassery et al. 2009).

\section{Signal transfer to the leaves and its implications.}

It has been demonstrated that a variety of stimuli (e.g., salt stress, abscissic acid, low oxygen) applied to barley roots are rapidly transferred to the leaves (Felle et al. 2005). Most interestingly, all of these stimuli were somehow transformed into a $\mathrm{pH}$ signal (alkalinization) that reached the leaf apoplast within minutes. Since the velocity of signal transfer depended on the transpiration rate, the xylem was assumed the most likely transducing system. We show here that chlamydospores are sensed by the roots and responded to with a $\mathrm{pH}$ shift (Figs. 1 to 3 ), which is subsequently transmitted within minutes as a $\mathrm{pH}$ signal to the leaf apoplast. However, in contrast to other stimuli applied to barley roots (Felle et al. 2005), the response to chlamydospores of $P$. indica was an acidification rather than an alkalinization. Although an apoplastic acidification could have more than one cause, an activation of the plasma membrane ATPase $\left(\mathrm{H}^{+}\right.$pump) that leads to activation of a number of transporters is likely. These transporters include, for instance, proton cotransporters, of which activation is essential for growth stimulation. Leaf apoplastic acidification instead of alkalinization also suggests that the root's encounter with $P$. indica is not sensed as stress, otherwise the apoplastic response should have been a pH increase (Felle et al. 2005; Wilkinson 1999).

\section{Effect of $P$. indica root colonization on the leaf response to pathogen inoculation.}

Leaf apoplast $\mathrm{pH}$ changes have been shown to be associated with specific interaction phenotypes in the barley- $B$. graminis pathosystem. We detected an apoplastic $\mathrm{pH}$ increase that commences about 24 hai of barley leaves with conidia of $B$. graminis f. sp. hordei race A6, which is virulent on cv. Ingrid (Fig. 3) (Felle et al. 2004). This $\mathrm{pH}$ increase was much more pronounced in leaves from plants pretreated with $P$. indica, indicating that the symbiotic fungus primes barley leaves for a stronger alkalinization response. This effect was demonstrated 5 days after inoculating the root system with chlamydospores, indicating that the primed status is stable and can be judged as a long-term effect. These data are consistent with earlier results showing that a pronounced alkalinization induced by powdery mildew fungus is specifically associated with increased barley defense reactions governed either by the specific $R$ genes 
Mla12 and Mlg or by chemical resistance inducers (Felle et al. 2004). There is neither a $\mathrm{pH}$ response to treatment with $P$. indica spores in the absence of a $B$. graminis f. sp. hordei challenge nor is there a $\mathrm{pH}$ response to root treatment with the MAMP Glc8 irrespective of a $B$. graminis f. sp. hordei challenge (Fig. 3). Together these data suggest that the alkalinization response is a consequence of a successful defense reaction. Consequently, we observed in this experimental setup that root inoculation with $P$. indica chlamydospores-as well as root treatment with the chemical resistance inducer BTHled to enhanced resistance of the leaves against powdery mildew fungus already 3 dai (Fig. 4), as previously observed in barley leaves 3 weeks after inoculation of the roots with $P$. indica (Waller et al. 2005).

The defense phenoptypes mediated by the R genes Mla12 and $M l$, as well as those induced by the chemical BTH or by $P$. indica are all associated with a hypersensitive reaction and, thus, with epidermal single-cell death that may result in a local apoplastic pH increase (Felle et al. 2004; Waller et al. 2005). On the other hand, alkalinization could serve the plant to inhibit fungal growth, e.g., by shifting the proton concentration far away from the optima of fungal effectors, e.g., those enzymes released for cell-wall softening.

In sum, we here confirm earlier results showing that $P$. indica, which is restricted to the root rhizodermis and to cortical cells (Deshmukh et al. 2006; Stein et al. 2008), induces in the monocotyledonous barley a systemic response against powdery mildew fungus. According to the growth pattern and short term of the transfer, it is feasible that $P$. indica generates one or more signals in the root outer tissue that reach the leaf epidermis via the xylem after a few minutes and that possibly reprogram barley leaves for a strong primed alkalinization response upon challenge inoculation with the powdery mildew fungus.

\section{MATERIALS AND METHODS}

Plant and fungal material and general growth conditions.

For root experiments, individual plants of Hordeum vulgare L. cv. Ingrid (Deutsche Saatveredelung, Lippstadt, Germany) were grown from seed under a 12-h light and 12-h dark regime at 20 to $25^{\circ} \mathrm{C}$. Seeds were surface-sterilized by soaking them for 3 to $4 \mathrm{~h}$ in diluted hypochlorite and were then rinsed four times in sterile tap water. Seedlings were then grown for 3 days on wet filter paper in a damp chamber. For measurements, intact seedlings were fixed to the bottom of a Plexiglas flow-through chamber and were incubated for 1 to $2 \mathrm{~h}$ in the respective basic solution $(1 \mathrm{mM} \mathrm{KCl}, 0.1 \mathrm{mM} \mathrm{NaCl}, 0.1 \mathrm{mM}$ $\mathrm{CaCl}_{2}$, and $0.5 \mathrm{mM} \mathrm{MES/TRIS} \mathrm{buffer)} \mathrm{mixed} \mathrm{to} \mathrm{the} \mathrm{bulk} \mathrm{pH}$ given in the figures.

For apoplast experiments, barley was grown under sterile conditions by placing sterilized seeds in 2.5-liter glass containers (Weck GmbH+Co KG, Wehr, Germany) filled with filter paper stacks soaked in autoclaved medium containing $\mathrm{CaCl}_{2}$ at $0.05 \mathrm{~g} /$ liter, $\mathrm{NaCl} 0.025$ at $\mathrm{g} / \mathrm{liter}, \mathrm{KH}_{2} \mathrm{PO}_{4}$ at $0.05 \mathrm{~g} /$ liter, $\left(\mathrm{NH}_{4}\right)_{2} \mathrm{HPO}_{4}$ at $0.025 \mathrm{~g} / \mathrm{liter}, \mathrm{MgSO}_{4} \times 7 \mathrm{H}_{2} \mathrm{O}$ at $0.15 \mathrm{~g} / \mathrm{liter}$, $\mathrm{FeCl}_{3}$ at $0.012 \mathrm{~g} /$ liter, and thiamine $\mathrm{HCl}$ at $0.1 \mathrm{mg} /$ liter, at $\mathrm{pH}$ 5.6 .

For powdery mildew resistance tests, barley plants were grown for 10 days in hydroponic culture as described. Inoculation with BTH $\left(40 \mathrm{mg} \mathrm{ml}^{-1}\right), P$. indica chlamydospores $\left(150,000\right.$ spores $\left.\mathrm{ml}^{-1}\right)$, or $0.1 \mu \mathrm{M}$ Glc8 was performed by immersing roots in the respective solutions for $10 \mathrm{~min}$ and returning the plants into hydroponic cultures. Chlamydospores were applied in a $0.05 \%$ Tween solution, which was also used as the mock treatment (control plants). Three days after treatment, the youngest fully expanded leaves were detached and inocu- lated with B. graminis f. sp. hordei conidia (8 to 12 spores per square millimeter). The number of $B$. graminis f. sp. hordei pustules was determined 6 dai.

$P$. indica (DSM11827 from Deutsche Sammlung von Mikroorganismen und Zellkulturen, Braunschweig, Germany), was propagated on agar plates prepared with modified Aspergillus minimal medium (Pham et al. 2004) kept at $25^{\circ} \mathrm{C}$ for 3 to 4 weeks. Chlamydospores were isolated from plates using a $0.05 \%$ Tween-20 solution collected at $500 \times g$ for $10 \mathrm{~min}$ and were resuspended in basic solution (discussed above) three times, resulting in a solution containing $P$. indica chlamydospores at the rate of $5 \times 10^{5} \mathrm{ml}^{-1}$. Inoculation with powdery mildew fungus was performed by shaking barley leaves heavily infected with Blumeria graminis f. sp. hordei A6 (Wiberg 1974) in an inoculation tower about $1 \mathrm{~m}$ above the leaves and manually circulating the air to ensure equal distribution of the spores. Inoculation density was counted using a counting plate of defined size placed beside the leaves.

\section{Recording surface $\mathbf{p H}$.}

The flow-through Plexiglas chamber permitted a horizontal approach of one or two microelectrodes. $\mathrm{pH}$-sensitive microelectrodes were positioned at the root surface using a micromanipulator (Narishige, Tokyo). Surface $\mathrm{pH}$ profiles were recorded as previously described (Felle 1998). By moving the electrodes from the bulk of the medium towards the surface at $90^{\circ}$, the difference between the two positions was attained. The electrode was then moved a certain distance along the root and the same procedure was repeated, and so on. For point measurements, $\mathrm{pH}$ microelectrodes were positioned at a certain root area and left there for the entire experiment. Before adding the spores, a constant flowthrough ( 3 to $4 \mathrm{ml} \mathrm{min}^{-1}$ ) of the medium was adjusted until a stable baseline was recorded. The spore suspension was added without changing the velocity of the flow.

\section{Apoplastic pH measurements.}

Apoplastic $\mathrm{pH}$ measurements were carried out as described (Felle et al. 2004). Intact barley plants were used throughout the experiments. Plants were kept in an Erlenmeyer flask,

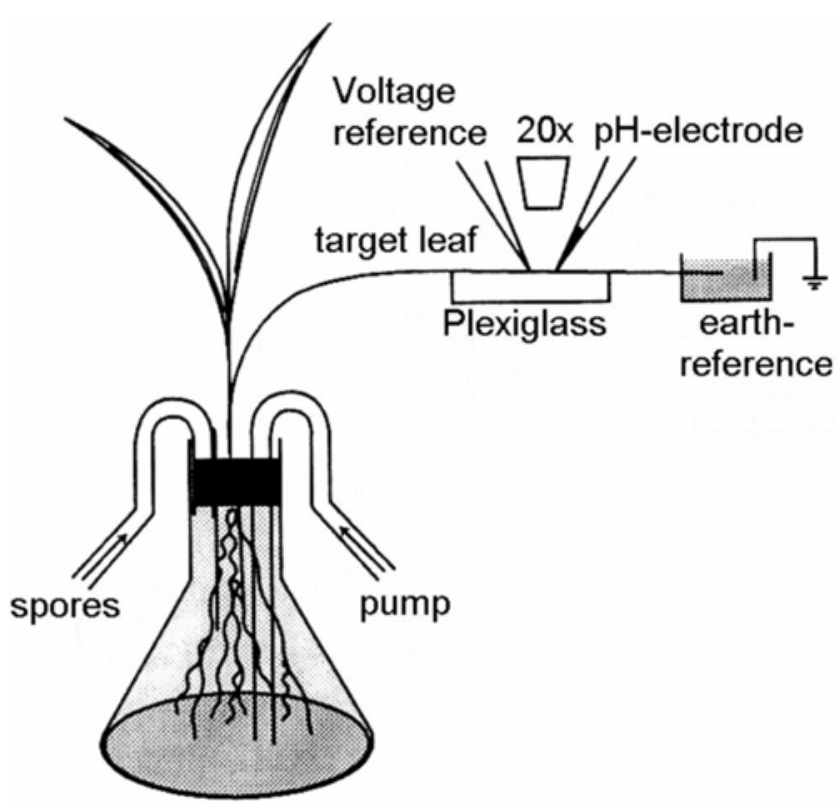

Fig. 5. Basic setup to measure apoplastic $\mathrm{pH}$ on an intact barley plant. Root system was submersed in a solution of $1 \mathrm{mM} \mathrm{KCl}, 0.1 \mathrm{mM} \mathrm{NaCl}$, and $0.1 \mathrm{mM} \mathrm{CaCl}_{2}$. 
which permitted continuous fluid exchange around the root system (Fig. 5). Roots were adapted to a basic solution of 1 $\mathrm{mM} \mathrm{KCl}, 0.1 \mathrm{mM} \mathrm{NaCl}$, and $0.1 \mathrm{mM} \mathrm{CaCl}_{2}$. One leaf (target leaf) was fixed with double-adhesive tape on a Plexiglas surface. Under optical control, the electrodes were positioned inside cavities of open stomata at an angle of approximately $45^{\circ}$, using a $20 \times$ long-distance objective. The earth-reference electrode was positioned at the end of the target leaf. Electrical contact was attained by bringing the electrodes into contact with the apoplastic fluid, which was signaled by the digital response of the amplifier.

\section{pH-sensitive microelectrodes.}

These have been fabricated and used as described before (Felle and Zimmermann 2007; Felle 1998). Briefly, all microprobes were fabricated from 1.5-mm glass tubing (Hilgenberg, Malsfeld, Germany). Capillaries were pulled on a two-stage puller (List-L/P-3P-A; Darmstadt, Germany) to tips of 2 to 5 $\mu \mathrm{m}$, which were heat-polished over a platinum wire. These capillaries were filled with $0.5 \mathrm{M} \mathrm{KCl}$ to be used as apoplastic voltage reference electrodes. To prepare $\mathrm{pH}$-sensitive electrodes, capillaries were heated to $200^{\circ} \mathrm{C}$ in an oven for $1 \mathrm{~h}$ and were silanized internally by repeatedly dipping the rear end of the hot capillaries into a $0.02 \%$ tributylsilane and chloroform solution. The capillaries were kept at $200^{\circ} \mathrm{C}$ for approximately $1 \mathrm{~h}$ before the silanization procedure was repeated. Silanized capillaries (cooled to room temperature) were backfilled with the respective sensor mixture (Fluka \#95297; Fluka Chemical Corp., Milwaukee, WI, U.S.A.) and were topped up with the reference solution (100 $\mathrm{mM}$ morpholineethanesulfonic acidTris, adjusted to $\mathrm{pH} 6,0.5 \mathrm{M} \mathrm{KCl}$ ). Electrodes were stored for several days before use. Ready-to-use electrodes were connected through a suitable electrode holder (World Precision Instruments, Sarasota, FL, U.S.A.) with a high-impedance $\left(10^{15} \mathrm{ohm}\right)$ amplifier (WPI-FD223; World Precision Instruments). Kinetics were recorded on a chart recorder (Linseis-L 2200; Linseis, Selb, Germany).

\section{ACKNOWLEDGMENTS}

The authors gratefully acknowledge financial support for this study by the Deutsche Forschungsgemeinschaft (FOR 666; Fe 213/16-1, 16-2, and WA 2478/1-1)

\section{LITERATURE CITED}

Achatz, B. 2006. Untersuchungen zum Einfluss des Wurzelendophyten Piriformospora indica auf das Wachstum von Hordeum vulgare, die Resistenz gegen Blumeria graminis f. sp. hordei und die Genexpression in den Blättern. Marburg, Germany. Ph.D. thesis. Philipps-University Marburg, Germany.

Baltruschat, H., Fodor, J., Harrach, B. D., Niemczyk, E., Barna, B., Gullner, G., Janeczko, A., Kogel, K. H., Schäfer, P., Schwarczinger, I., Zuccaro, A., and Skoczowski, A. 2008. Salt tolerance of barley induced by the root endophyte Piriformospora indica is associated with a strong increase in antioxidants. New Phytol. 180:501-510.

Baureithel, K., Felix, G., and Boller, T. 1994. Specific, high affinity binding of chitin fragments to tomato cells and membranes. Competitive inhibition of binding by derivatives of chitooligosaccharides and a Nod factor of Rhizobium. J. Biol. Chem. 269:17931-17938.

Deshmukh, S., and Kogel, K.-H. 2007. Piriformospora indica protects barley from root rot disease caused by Fusarium graminearum. J. Plant Dis. Prot. 114:263-268.

Deshmukh, S., Hückelhoven, R., Schäfer, P., Imani, J., Sharma, M., Weiss, M., Waller, F., and Kogel, K.-H. 2006. The root endophytic fungus Piriformospora indica requires host cell death for proliferation during mutualistic symbiosis with barley. Proc. Natl. Acad. Sci. U.S.A. 103:18450-18457.

Ehrhardt, D. W., Atkinson, E. M., and Long, S. R. 1992. Depolarization of alfalfa root hair membrane potential by Rhizobium meliloti Nod factors. Science 256:998-1000.
Felle, H. H. 1998. The apoplastic $\mathrm{pH}$ of Zea mays root cortex as measured with $\mathrm{pH}$-sensitive microelectrodes: Aspects of regulation. J. Exp. Bot. 49:987-995.

Felle, H. H., and Hanstein, S. 2002. The apoplastic pH of the substomatal cavity of Vicia faba leaves and its regulation responding to different stress factors. J. Exp. Bot. 53:73-82.

Felle, H. H., Kondorosi, É., Kondorosi, Á., and Schultze, M. 1998. The role of ion fluxes in nod factor signaling in Medicago sativa. Plant $\mathrm{J}$. 13:455-463.

Felle, H. H., Herrmann, A., Hanstein, S., Hückelhoven, R., and Kogel, K.H. 2004. Apoplastic pH signaling in barley leaves attacked by the powdery mildew fungus Blumeria graminis f. sp. hordei. Mol. PlantMicrobe Interact. 17:118-123.

Felle, H. H., Herrmann, A., Hückelhoven, R., and Kogel, K.-H. 2005. Root-to-shoot signaling: Apoplastic alkalinisation, a general stress signal and defence factor in barley (Hordeum vulgare). Protoplasma 227:17-24.

Felle, H. H., and Zimmermann M. R. 2007. Systemic signaling in barley through action potentials. Planta 226:203-214.

Felle, H. H., Herrmann, A., Schäfer, P., Hückelhoven, R., and Kogel, K.-H. 2008. Interactive signal transfer between host and pathogen during successful infection of barley leaves by Blumeria graminis and Bipolaris sorokiniana. J. Plant Physiol. 165:52-59.

Felix, G., Regenass, M., and Boller, T. 1993. Specific perception of subnanomolar concentrations of chitin fragments by tomato cells: Induction of extracellular alkalinization, changes in protein phosphorylation, and establishment of a refractory state. Plant J. 4:307-316.

Monshausen, G. B., Zieschang, H. E., and Sievers, A. 1996. Differential proton secretion in the apical elongation zone caused by gravi-stimulation is induced by a signal from the root cap. Plant Cell Environ. 19:1408-1414

Pham, G. H., Kumari, R., Singh, A., Malla, R., Prasad, R., Sachdev, M., Kaldorf, M., Buscot, F., Oelmüller, R., Hampp, R., Saxena, A. K., Rexer, K. H., Kost, G., and Varma, A. 2004. Axenic culture of symbiotic fungus Piriformospora indica. Pages 593-612 in: Plant Surface Microbiology. A. Varma, L. Abbot, D. Werner, and R. Hampp, eds. Springer, Berlin.

Radutoiu, S., Madsen, L. H., Madsen, E. B., Felle, H. H., Umehara, Y., Grønlund, M., Sato, S., Nakamura, Y., Satoshi, T., Sandal, N., and Stougaard, J. 2003. Plant recognition of symbiotic bacteria requires two LysM receptor-like kinases. Nature 425:585-592.

Schäfer, P., Khatabi, B., and Kogel, K.-H. 2007. Recent advances in the study of Piriformospora indica, challenges and perspectives. FEMS (Fed. Eur. Microbiol. Soc.) Microbiol. Lett. 275:1-7.

Schäfer, P., and Kogel, K.-H. 2009. The Sebacinoid fungus Piriformospora indica: An orchid mycorrhiza with a robust endophytic potential for reprogramming host plants for increased reproduction and fitness. Pages 99-112 in: The Mycota Vol. V, Plant Relationships. 2nd ed. H. B. Deising, ed. Springer, Berlin.

Schäfer, P., Pfiffi, S., Voll, L.M., Zajic, D., Chandler, P. M., Waller, F. Scholz, U., Pons-Kühnemann, J., Sonnewald, S., Sonnewald, U., Kogel, K. H. Gibberellin contributes to compatibility of barley roots to the mycorrhiza fungus Piriformospora indica. Plant J. In press.

Serfling, A., Wirsel, S. G. R, Lind, V., and Deising, H. B. 2007. Performance of the biocontrol fungus Piriformospora indica on wheat under greenhouse and field conditions. Phytopathology 97:523-531.

Stein, E., Molitor, A., Kogel, K.-H., and Waller, F. 2008. Systemic resistance in Arabidopsis conferred by the mycorrhiza fungus Piriformospora indica requires jasmonic acid signaling and the cytoplasmic function of NPR1. Plant Cell Physiol. 49:1747-1751.

Vadassery, J., Ranf, S., Drzewiecki, C., Mithöfer, A., Mazars, C., Scheel, D., Lee, J., and Oelmüller, R. 2009. A cell wall extract from the endophytic fungus Piriformospora indica promotes growth of Arabidopsis seedlings and induces intracellular calcium elevation in roots. Plant $\mathrm{J}$. 59:193-206.

Van Loon, L. C., Bakker, P. A. H. M., and Pieterse, C. M. J. 1998. Systemic resistance induced by rhizosphere bacteria. Annu. Rev. Phytopathol. 36:453-83.

Van Wees, S. C. M., Van der Ent, S., and Pieterse C. M. J. 2008. Plant immune responses triggered by beneficial microbes. Curr. Opin. Plant Biol. 11:443-448.

Vera-Estrella, R., Barckla, B. J., Higgins, V. J., and Blumwald, E. 1994. Plant defense response to fungal pathogens. I. Activation of host plasma membrane $\mathrm{H}^{+}$-ATPase by elicitor-induced enzyme depolarization. Plant Physiol. 104:209-215.

Verma, S., Varma, A., Rexer, K.-H., Hassel, A., Kost, G., Sarabhoy, A., Bisen, P., Bütenhorn, B., and Franken, P. 1998. Piriformospora indica, gen. nov. sp. nov., a new root-colonizing fungus. Mycologia 90:896-903.

Waller, F., Achatz, B., Baltruschat, H., Fodor, J., Becker, K., Fischer, M., Heier, T., Hückelhoven, R., Neumann, C., von Wettstein, D. 
Franken, P., and Kogel, K.-H. 2005. The endophytic fungus Piriformospora indica reprograms barley to salt-stress tolerance, disease resistance, and higher yield. Proc. Natl. Acad. Sci. U.S.A. 102:13386-13391.

Waller, F., Mukherjee, K., Deshmukh, S. D., Achatz, B., Sharma, M., Schäfer, P., and Kogel, K.-H. 2008. Systemic and local modulation of plant responses by Piriformospora indica and related Sebacinales spe- cies. J. Plant Physiol. 165:60-70.

Weisenseel, M. H., Dorn, A., and Jaffe, L. F. 1979. Natural $\mathrm{H}^{+}$currents traverse growing roots and root hairs of barley (Hordeum vulgare L.). Plant Physiol. 64:512-518.

Wiberg, A. 1974. Genetical studies of spontaneous sources of resistance to powdery mildew in barley. Hereditas 77:89-148.

Wilkinson, S. 1999. pH as a stress signal. Plant Growth Reg. 29:87-99. 